\title{
Cardiac reoperation: Should that be a marker of quality?
}

\author{
Bahaaldin Alsoufi, MD
}

\footnotetext{
From the Department of Cardiovascular and Thoracic Surgery, University of Louisville School of Medicine, Norton Children's Hospital, Louisville, Ky.

Disclosures: Author has nothing to disclose with regard to commercial support.

Received for publication July 8, 2018; accepted for publication July 10, 2018; available ahead of print Aug 7, 2018.

Address for reprints: Bahaaldin Alsouf, MD, Department of Cardiovascular and Thoracic Surgery, University of Louisville School of Medicine, Norton Children's Hospital, 201 Abraham Flexner Way, Suite 1200, Louisville, KY 40202 (E-mail: balsoufi@ hotmail.com).

J Thorac Cardiovasc Surg 2018;156:1959-60

$0022-5223 / \$ 36.00$

Copyright (c) 2018 by The American Association for Thoracic Surgery

https://doi.org/10.1016/j.jtcvs.2018.07.015
}

Outcomes of surgical repair and palliation of congenital heart disease have improved remarkably in the past 1 to 2 decades as a result of numerous advances in cardiac imaging, preoperative stabilization, surgical strategies, perfusion techniques, and perioperative care. Along with those developments have come higher expectations from families, referring physicians, insurance companies, and hospital administration. In the same time frame, various multiinstitutional surgical and critical care registries were created, with the aim of using those large databases for risk assessment, clinical outcome research, benchmarking and evaluation of program performance, and implementation of quality improvement projects. ${ }^{1-4}$ Recently, there has been an increased emphasis on transparency and public reporting of institutional outcomes, with the goal of providing families with valuable information while simultaneously encouraging programs to achieve superior outcomes. Although those objectives are uniformly desired, a considerable skepticism was legitimately generated because of the lack of ideal risk-stratification models that take into consideration the numerous demographic, clinical, and anatomic variables that intimately influence outcomes. This uncertainty was accompanied by concerns about negative implications of public reporting, such as risk aversion, program regression, and potential effects on government regulation and reimbursement strategies.

Multiple surgical risk-stratification models have been developed; however, many of those are procedure related and are based mainly on expert opinion. ${ }^{5}$ The subsequent creation of large congenital heart surgery databases has allowed analysis of 77,294 operations entered into the congenital heart surgery databases of the Society of Thoracic Surgeons ( $n=43,934$ patients) and the European Congenital Heart Surgeons Association and European Association for Cardio-Thoracic Surgery $(\mathrm{n}=33,360$ patients). These database analyses consequently allowed the development of a classification that was based on objective rather than subjective data, the Society of Thoracic anomalies). ${ }^{3,4}$

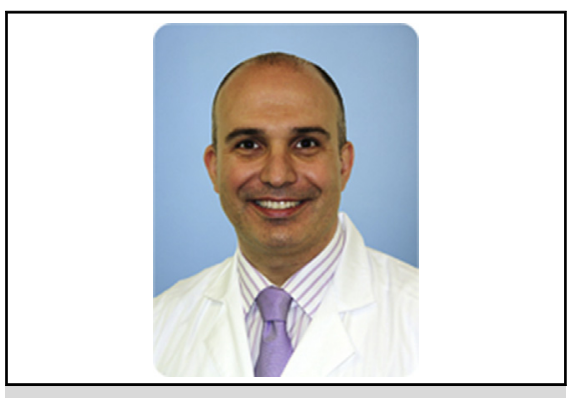

Bahaaldin Alsoufi, MD

Central Message

Use of registry-derived cardiac reoperations as a quality marker is limited by lack of data granularity to differentiate expected reoperations from those related to complications or residual lesions.

See Article page 1961.

Surgeons-European Association for Cardiothoracic Surgeons Congenital Heart Surgery Mortality Categories (STAT Mortality Categories). ${ }^{3,4}$ Subsequent refinements of the STAT Mortality Categories are underway in an effort to perform more sophisticated risk adjustment that takes into account various clinical and demographic factors (for example, genetic syndromes and extracardiac

In the current issue of the Journal, Gupta and colleagues ${ }^{6}$ focus on one clinical variable that can influence outcomes after congenital cardiac surgery, and that is cardiac reoperation within the same admission for index operation. Their hypothesis is that the STAT Mortality Categories riskstratification system centers on the initial (index) operation, and that in some cases the subsequent reoperation might be more complex and associated with a higher STAT category; therefore classifying patients according to the procedure of highest complexity, rather than the index operation, would thus likely change the ratio of observed to predicted mortality for that patient. To study their hypothesis, they examined data from the Virtual Pediatric Systems Database on children younger than 18 years old who had undergone congenital cardiac surgery, with or without cardiopulmonary bypass, between 2009 and 2015, and limited their patient cohort to those who underwent at least 1 cardiac reoperation $(22,393 / 51,047$ patients). Naturally, they found that in an important number of patients $(7691 / 22,393,34 \%)$, the cardiac reoperation was associated with a higher complexity 
STAT category. As a result, by assigning patients to the higher complexity operation category rather than the index operation, the number of patients in the lower STAT category decreased and the number of those in the higher STAT category increased. Not surprisingly, the ratio of observed to predicted mortality was higher when patients were assigned to the lower STAT category of the index operation rather than to that of the succeeding, higher complexity operation. Naturally, this difference was highest in patients with lower index STAT categories (I, II, and III), and it was also true for extracorporeal membrane oxygenation use, cardiac arrest, and other major surgical complications.

Although the results of this study are straightforward and expected, the question arises in this era as to how to use cardiac reoperation as a marker of quality and how to incorporate that into a model that is used to assess program performance. Cardiac reoperation can be planned as a staged strategy in the treatment of patients with complex congenital cardiac anomalies (eg, pacemaker implantation for cardiomyopathy followed by heart transplantation, coarctation repair followed by atrioventricular septal defect repair, palliative aortic valvuloplasty followed by Ross-Konno operation) or with clinical conditions that prohibit a single stageapproach (eg, pulmonary artery branch banding followed by Norwood operation in patients deemed to face a high risk with a primary Norwood operation, coarctation repair followed by arterial switch and ventricular septal defect closure in very small neonates). On the other hand, cardiac reoperation may be unplanned as a result of a missed diagnosis, residual lesion, or surgical complication (atrioventricular valve replacement after partial atrioventricular septal defect repair, tricuspid valve repair after ventricular septal defect closure, aortic or mitral valve repair after subaortic membrane resection, pulmonary vein stenosis repair after repair or palliation of other cardiac lesions, aortic arch repair for a previously unidentified aortic obstruction, ascending aortic replacement for iatrogenic aneurysm or obstruction, pacemaker implantation after ventricular septal defect closure, pulmonary artery banding for a residual intracardiac shunt, aortopulmonary shunt for residual pulmonary artery obstruction, and Norwood operation after pulmonary artery banding for single-ventricle anomalies and unrecognized systemic outflow tract obstruction, to name a few).

Cardiac reoperation thus may be a marker of poor performance, especially when it is unplanned because of missed diagnosis, surgical complication, or residual lesion; in contrast, it may be a marker of excellence in centers that are taking on patients at very high risk and implementing thoughtful staged approaches to overcome the many clinical and anatomic challenges that these patients might pose. In $34 \%$ of cases in the study by Gupta and colleagues ${ }^{6}$ cardiac reoperation was more complex and could be assigned to a higher STAT category. When cardiac reoperation is unplanned, assigning the patient to the highest complexity operation rather than the intended index operation might seem like turning a blind eye to poor performance in a majority of instances. On the other hand, when cardiac reoperation is planned or expected, assigning the patient to the highest complexity operation rather than the index operation might be the fair thing to do for centers taking care of patients whose care is complex and high risk. The question arises whether the current registry databases are granular enough to differentiate those completely different groups of cardiac reoperations to allow the use of their data for assessment of program performance. My guess is that the answer is no. Although the article by Gupta and colleagues ${ }^{6}$ may seem to be stating the obvious, it does highlight another limitation of the current risk-stratification models and call attention to another area where refinements of those models can be attempted, with the aim of creating an ideal system that serves the objectives of quality improvement while being fair and truly representative of truthful risk at the same time.

\section{References}

1. Jacobs JP, Mayer JE Jr, Pasquali SK, Hill KD, Overman DM, St Louis JD, et al. The Society of Thoracic Surgeons congenital heart surgery database: 2018 update on outcomes and quality. Ann Thorac Surg. 2018;105:680-9.

2. Jacobs ML, Jacobs JP, Hill KD, Hornik C, O'Brien SM, Pasquali SK, et al. The Society of Thoracic Surgeons congenital heart surgery database: 2017 update on research. Ann Thorac Surg. 2017;104:731-41.

3. O'Brien SM, Jacobs JP, Pasquali SK, Gaynor JW, Karamlou T, Welke KF, et al. The Society of Thoracic Surgeons congenital heart surgery database mortality risk model: part 1-statistical methodology. Ann Thorac Surg. 2015; 100:1054-62.

4. Jacobs JP, O’Brien SM, Pasquali SK, Gaynor JW, Mayer JE Jr, Karamlou T, et al. The Society of Thoracic Surgeons congenital heart surgery database mortality risk model: part 2-clinical application. Ann Thorac Surg. 2015;100:1063-8; discussion $1068-70$.

5. Jacobs JP, Jacobs ML, Lacour-Gayet FG, Jenkins KJ, Gauvreau K, Bacha E, et al. Stratification of complexity improves the utility and accuracy of outcomes analysis in a multi-institutional congenital heart surgery database: application of the risk adjustment in congenital heart surgery (RACHS-1) and Aristotle systems in the Society of Thoracic Surgeons (STS) congenital heart surgery database. Pediatr Cardiol. 2009;30:1117-30.

6. Gupta P, Rettiganti M, Shinkawa T, Gossett JM, Brundage N, Jeffries HE, et al. Reclassifying by highest complexity operation rather than first operation influences mortality after pediatric heart surgery. J Thorac and Cardiovasc Surg. 2018;156:1961-7. 